Int. J. Electrochem. Sci., 15 (2020) $10104-10116$

\title{
Decreasing Weight Particle Swarm Optimization Combined with Unscented Particle Filter for the Non-Linear Model for Lithium Battery State of Charge Estimation
}

\author{
Lei Chen, Shunli Wang ${ }^{*}$, Hong Jiang, Carlos Fernandez, Chunyun Zou \\ School of Information Engineering, Southwest University of Science and Technology, Mianyang \\ 621010 \\ *E-mail: $497420789 @$ qq.com
}

doi: $10.20964 / 2020.10 .41$

Received: 5 June 2020 / Accepted: 20 July 2020 / Published: 31 August 2020

\begin{abstract}
Accurate estimation of State of Charge (SOC) of wireless sensor network nodes is of great significance for wireless sensor network layout. A combination strategy method based on unscented particle filter using weight particle swarm optimization (PSO-UPF) algorithm is proposed to improve estimation accuracy. The particle filter (PF) algorithm is usually used to deal with nonlinear problems, easily falling into particle degeneration and particle shortage. The unscented particle filter (UPF) algorithm can overcome the shortcomings by using the unscented Kalman filter (UKF) to generate the importance density function. Meanwhile, the particle swarm optimization (PSO) algorithm could improve the resampling process to solve particle shortage. Thus, the combination strategy improves the importance density function and the resampling method simultaneously. With the simulation comparison of PF, UPF and PSO-UPF algorithms, the results show that the proposed algorithm has higher estimation accuracy with the root mean square error less than $1 \%$. Furthermore, the proposed algorithm could achieve good accuracy with few particles, which could save running time and improve the estimate efficiency.
\end{abstract}

Keywords: State of Charge; particle filter; unscented particle filter; linearly decreasing weight particle swarm optimization

\section{FULL TEXT}

(C) 2020 The Authors. Published by ESG (www.electrochemsci.org). This article is an open access article distributed under the terms and conditions of the Creative Commons Attribution license (http://creativecommons.org/licenses/by/4.0/). 